\title{
Transformar nuestro mundo
}

La resolución 70/1 de la Asamblea General de la Organización de las Naciones Unidas aprobada en septiembre de 2015 lleva por título: Transformar nuestro mundo: La agenda 2030 para el Desarrollo Sostenible, la cual establece una visión transformadora hacia la sostenibilidad económica, social y ambiental de los 193 Estados Miembros.

La interesante propuesta global se integra por 17 objetivos de desarrollo sostenible (ODS) y 167 metas que constituyen una hoja de ruta tanto en el ámbito nacional como el ámbito local, lo que significa la oportunidad de que evaluemos el lugar en donde estamos y planifiquemos hacia donde queremos llegar, para lo cual es necesario la identificación de metas a largo plazo que estén orientadas a lograr un desarrollo sostenible, inclusivo y en armonía con el medio ambiente.

Es el resultado de un trabajo conjunto entre los Estados miembros de las Naciones Unidas junto a un gran numero de actores de la sociedad civil, el mundo académico y el sector privado que conformaron un proceso de negociación abierto, democrático y participativo, que sitúa la igualdad y dignidad de las personas en el centro del desarrollo sostenible, es un llamando de alianza mundial reforzada entre todos los países, sean desarrollados o en vías de desarrollo, que busca ser transformadora.

Dichos Objetivos del Desarrollo Sostenible son: 1) Poner fin a la pobreza en todas sus formas en todo el mundo; 2) Poner fin al hambre, lograr la seguridad alimentaria y la mejora de la nutrición y proponer la agricultura sostenible; 3) Garantizar una vida sana y promover el bienestar para todos en todas las edades; 4) Garantizar una educación inclusiva, equitativa y de calidad y promover oportunidades de aprendizaje durante toda la vida para todos; 5) Lograr la igualdad entre los géneros y empoderar a todas las mujeres y niñas; 6) Garantizar la disponibilidad de agua y su gestión sostenible y el saneamiento 
para todos; 7) Garantizar el acceso a una energía asequible, segura, sostenible y moderna para todos; 8) Promover el crecimiento económico sostenido, inclusivo y sostenible, el empleo pleno y productivo y el trabajo decente para todos; 9) Construir infraestructuras resilientes, promover la industrialización inclusiva y sostenible y fomentar la innovación; 10) Reducir la desigualdad en y entre los países; 11) Lograr que las ciudades y los asentamientos humanos sean inclusivos, seguros, resilientes y sostenibles; 12) Garantizar modalidades de consumo y producción sostenibles; 13) Adoptar medidas urgentes para combatir el cambio climático y sus efectos; 14) Conservar y utilizar en forma sostenible los océanos, los mares y los recursos marinos para el desarrollo sostenible; 15) Promover el uso sostenible de los ecosistemas terrestres, luchar contra la desertificación, detener e invertir la degradación de las tierras y frenar la pérdida de la diversidad biológica; 16) Promover sociedades pacificas e inclusivas para el desarrollo sostenible, facilitar el acceso a la justicia para todos y crear instituciones eficaces, responsables e inclusivas a todos los niveles; 17) Fortalecer los medios de ejecución y revitalizar la Alianza Mundial para el desarrollo sostenible.

Para hacer realidad los objetivos de desarrollo sostenible habrá que crearse de manera local y nacional instrumentos de monitoreo y evaluación así como sistematizar las propuestas para la elaboración de políticas publicas que nos permitan transformar nuestro mundo.

Desde nuestra trinchera, nosotros los abogados, académicos, litigantes o funcionarios públicos debemos de manera organizada y progresiva trabajar por repensar el derecho y las instituciones jurídicas, los retos son grandes: Prevenir la violencia generalizada; combatir la delincuencia; la corrupción; fortalecer el Estado de Derecho y la legalidad; lograr el acceso a la información; a la transparencia y la rendición de cuentas; incentivar la participación ciudadana; entre otros temas, que sin duda alguna dan evidencia de que vivimos en una nueva época de Derecho Global.

Guadalajara, Jalisco, verano de 2017 Dra. Silvia Patricia López González 